\title{
The behavior pattern of parents of patients with subacute sclerosing panencephalitis concerning alternative medicine
}

\author{
Sedat Işıkay ${ }^{1,2}$ \\ ${ }^{1}$ Department of Pediatric Neurology, Hasan Kalyoncu University, ${ }^{2}$ Department of Pediatric Neurology, Medical Park \\ Hospital, Gaziantep, Turkey.E-mail: dr.sedatisikay@mynet.com \\ Received: 1st December 2016, Revised: 6th January 2017, Accepted: 6th January 2017
}

SUMMARY: Işıkay S. The behavior pattern of parents of patients with subacute sclerosing panencephalitis concerning alternative medicine. Turk J Pediatr 2017; 59: 288-294.

The aim of the study was to examine the attitude of the parents of Subacute Sclerosing Panencephalitis (SSPE) patients regarding alternative treatment methods and compare with those of the parents of epilepsy patients. The study comprised 39 SSPE and 53 epilepsy patients who were under follow-up in Gaziantep Children's Hospital. A questionnaire designed to inquire about the knowledge (13 questions) and behavior (11 questions) of parents about alternative medicine methods was given to the caregiver of all patients. The ratio of parents using alternative medicine methods was $29 / 39(74.4 \%)$ in the SSPE group and $8 / 53(15.1 \%)$ in the epilepsy group. Less than half of the parents of SSPE patients reported talking about it with their doctors. These results show parents facing a chronic debilitating disease frequently seek benefit from alternative methods. Most define this treatment as complementary to the established medical treatment. However, potential and unrecognized adverse events of alternative methods and their interference with regular medical treatment can be of importance, especially because treating physicians are seldom informed about concurrent use.

Key words: subacute sclerosing panencephalitis, epilepsy, questionnaire, alternative medicine, pediatric, parent, children.

Subacute sclerosing panencephalitis (SSPE) is progressive and often fatal encephalitis caused by persistent measles virus infection in the central nervous system ${ }^{1}$. Incidence rates in different parts of the world range between 0.2 to 40 cases per million population per year ${ }^{2,3}$. Current treatments may reduce the progression rate, extend survival, or rarely, result in clinical improvement in only $35-45 \%$ of patients ${ }^{4,5}$.

The term "alternative and complementary medicine" comprises all treatment other than scientifically established methods ${ }^{6}$. The usage of complementary and alternative treatment methods is increasing all over the world especially for chronic diseases with high economical and emotional burden ${ }^{7}$. Determining the general tendency of patients or caregivers about alternative treatment methods may increase understanding by doctors who generally disapprove this practice.
We investigated the usage of alternative treatment method for SSPE patients and compared the results with those of epilepsy patients. To the best of our knowledge, this is the first such study on SSPE or any fatal neurological disease in children.

\section{Material and Methods}

\section{Study design and patient selection}

The study comprised 39 SSPE and 53 epilepsy patients who were under follow-up in Gaziantep Children's Hospital. A questionnaire designed to inquire about the knowledge (13 questions) and behavior (11 questions) of parents about alternative medicine methods was given to the caregiver of all patients. The questionnaires were filled out by the parents themselves. The diagnosis of SSPE was made according to clinical and laboratory criteria. All patients had elevated measles IgG titer in the cerebrospinal 
fluid. Duration of disease was 48-184 months (median 114 months). Twenty-seven (69.2\%) patients were bed-ridden. In the epilepsy group, 31 patients were under monotherapy, 10 were receiving two drugs and the remaining 12 cases were taking three or more drugs for treatment. Cerebral palsy was an associated diagnosis in 13 patients of the epilepsy group.

The study was approved by the local ethics committee and informed consent was obtained from the parents of all participants.

\section{Statistical Analyses}

Results were expressed as number and percentage. Comparisons of two groups were performed with Student's t test. $\mathrm{P}<0.05$ was considered as statistically significant. All statistical analyses were performed with the Statistical Package for Social Sciences (SPSS) for Windows 21.0 program.

\section{Results}

A total of 39 SSPE (13 female, 26 male) and 53 epilepsy ( 30 female, 23 male) patients were included in the study. General characteristics are summarized in Table I. Most parents in both groups were primary school graduates with middle- or low-income. Most mothers were stay at home mothers and the primary caregiver for the child.

The knowledge of parents about alternative medicine, as assessed with 13 questions in the questionnaire, showed most parents in both groups knew about at least one type of alternative medicine method (Table II). Knowledge about herbs' effect on health was less prevalent than belief in metaphysical factors' effect. Many parents defined the alternative treatment methods as the last chance where medical treatment is not enough. Very few patients defined the alternative treatment as a first line therapy before presenting to a doctor.

The behavior of parents about alternative medicine was evaluated by 11 questions (Table III). Significantly fewer parents in the SSPE group had been informed about the course of the disease compared with the epilepsy group. Significantly more parents in the SSPE group had applied alternative medicine methods to their child before the diagnosis, and had spent significantly higher amounts for the alternative methods in the SSPE group compared with the epilepsy group.

\section{Discussion}

In this general assessment of the attitude of parents about alternative medicine methods, we observed a significant difference between SSPE and epilepsy groups: $75 \%$ vs. $20 \%$. This result could be expected due to the progressive and debilitating nature of SSPE and the absence of any proven treatment. Moreover, the educational level and economic status of parents were lower in the SSPE group, which may also contribute to this difference. Interestingly, 7/29 parents who used alternative treatment methods reported to be advised by the doctors about this method. Fortunately, adverse events were reported in only 2 cases and $26 / 29$ parents $(89.6 \%$ ) were defining alternative treatment as complementary to medical treatment. There was no difference between groups regarding the presence of adverse events and general opinion of parents about this treatment modality.

This is the first study evaluating the behavior of parents of SSPE patients about alternative treatment methods. More studies have been reported about epilepsy. In one from Turkey in which the parents of 202 epilepsy patients were interviewed face-to-face, $27.7 \%$ reported used alternative treatment including $6.9 \%$ who started it at the suggestion of their doctor ${ }^{8}$. In our study, 8 of $53(15.1 \%)$ parents of the epilepsy group applied alternative treatment methods and none of them reported this having been suggested by their doctor. In fact, the figures in our study are in general lower than those in the literature. Peebles et al. ${ }^{9}$ evaluated the prevalence, characteristics, and demographic patterns of alternative medicine use in 92 patients with epilepsy and reported $24 \%$ of patients were using these methods. Recently, Lagunju et al. ${ }^{10}$ applied a standardized questionnaire to caregivers of 175 children with epilepsy: $56.6 \%$ had a history of alternative medicine usage, of which $1 / 3$ in combination with prescribed anti-epileptic drugs, and $17.1 \%$ reported adverse effects. The use of alternative medicine was less frequent in our epilepsy group: this may be related to the less severe nature of epilepsy compared to SSPE, and also 
Table I. General Characteristic of Study Participants.

\begin{tabular}{|c|c|c|c|}
\hline & $\operatorname{SSPE}(n=39)$ & Epilepsy $(n=53)$ & $\mathrm{p}$ \\
\hline Age (years) & $16.07 \pm 1.73$ & $15.58 \pm 1.02$ & 0.12 \\
\hline \multicolumn{3}{|l|}{ Pollster (\%) } & 0.07 \\
\hline Mother & $21(53.8)$ & $31(58.5)$ & \\
\hline Father & $15(38.5)$ & $22(41.5)$ & \\
\hline Other & $3(7.7)$ & 0 & \\
\hline Gender (F/M) & $13 / 26$ & $30 / 23$ & 0.39 \\
\hline \multicolumn{4}{|l|}{ Mother's education (\%) } \\
\hline None & $7(17.9)$ & $5(9.4)$ & 0.01 \\
\hline Primary School & $28(71.8)$ & $36(67.8)$ & \\
\hline Secondary School & $2(5.1)$ & $9(16.9)$ & \\
\hline High School & & $1(1.8)$ & \\
\hline University & $2(5.1)$ & $2(3.6)$ & \\
\hline \multicolumn{4}{|l|}{ Mother's occupation (\%) } \\
\hline Office & $1(2.6)$ & $1(1.8)$ & 0.07 \\
\hline Worker & 0 & $5(9.0)$ & \\
\hline Employer & 0 & $1(1.8)$ & \\
\hline Homemaker & $38(97.4)$ & $46(86.8)$ & \\
\hline \multicolumn{3}{|l|}{ Father's education (\%) } & 0.10 \\
\hline None & $5(12.8)$ & $1(1.8)$ & \\
\hline Primary School & $25(64.1)$ & $29(54.7)$ & \\
\hline Secondary School & $4(10.2)$ & $9(16.9)$ & \\
\hline High School & $4(10.2)$ & $11(20.7)$ & \\
\hline University & $1(2.6)$ & $2(3.6)$ & \\
\hline \multicolumn{3}{|l|}{ Father's occupation (\%) } & 0.001 \\
\hline Office & $5(12.8)$ & $7(13.2)$ & \\
\hline Worker & $8(20.5)$ & $38(71.7)$ & \\
\hline Employer & $23(58.9)$ & $7(13.2)$ & \\
\hline Unemployed & $3(7.7)$ & 0 & \\
\hline \multicolumn{3}{|l|}{ Care giver (\%) } & 0.24 \\
\hline Mother & $34(87.2)$ & $47(88.7)$ & \\
\hline Father & $1(2.6)$ & $5(9.0)$ & \\
\hline Other & $3(7.7)$ & $1(1.8)$ & \\
\hline \multicolumn{3}{|l|}{ Economic situation (\%) } & 0.005 \\
\hline Good & $4(10.2)$ & $4(7.2)$ & \\
\hline Middle & $10(25.6)$ & $33(62.3)$ & \\
\hline Lower middle & $12(30.7)$ & $10(18.0)$ & \\
\hline Low & $12(30.7)$ & $6(10.8)$ & \\
\hline \multicolumn{3}{|l|}{ Health Insurance (\%) } & 0.001 \\
\hline None & $8(20.5)$ & $3(5.4)$ & \\
\hline Superannuation fund & $8(20.5)$ & $3(5.4)$ & \\
\hline Social security & $8(20.5)$ & $38(71.7)$ & \\
\hline Distinctive fund & $6(15.4)$ & $2(3.6)$ & \\
\hline Private insurance & $7(17.9)$ & $1(1.8)$ & \\
\hline National* & 0 & $6(11.3)$ & \\
\hline \multicolumn{3}{|l|}{ Area of residence $(\%)$} & 0.09 \\
\hline Village & $5(12.8)$ & $9(16.9)$ & \\
\hline Town & $8(20.5)$ & $18(33.9)$ & \\
\hline Province & $23(58.9)$ & $25(47.2)$ & \\
\hline *Equivalent to Medicaid in USA. & & & \\
\hline
\end{tabular}


Table II. Knowledge About Alternative Medicine.

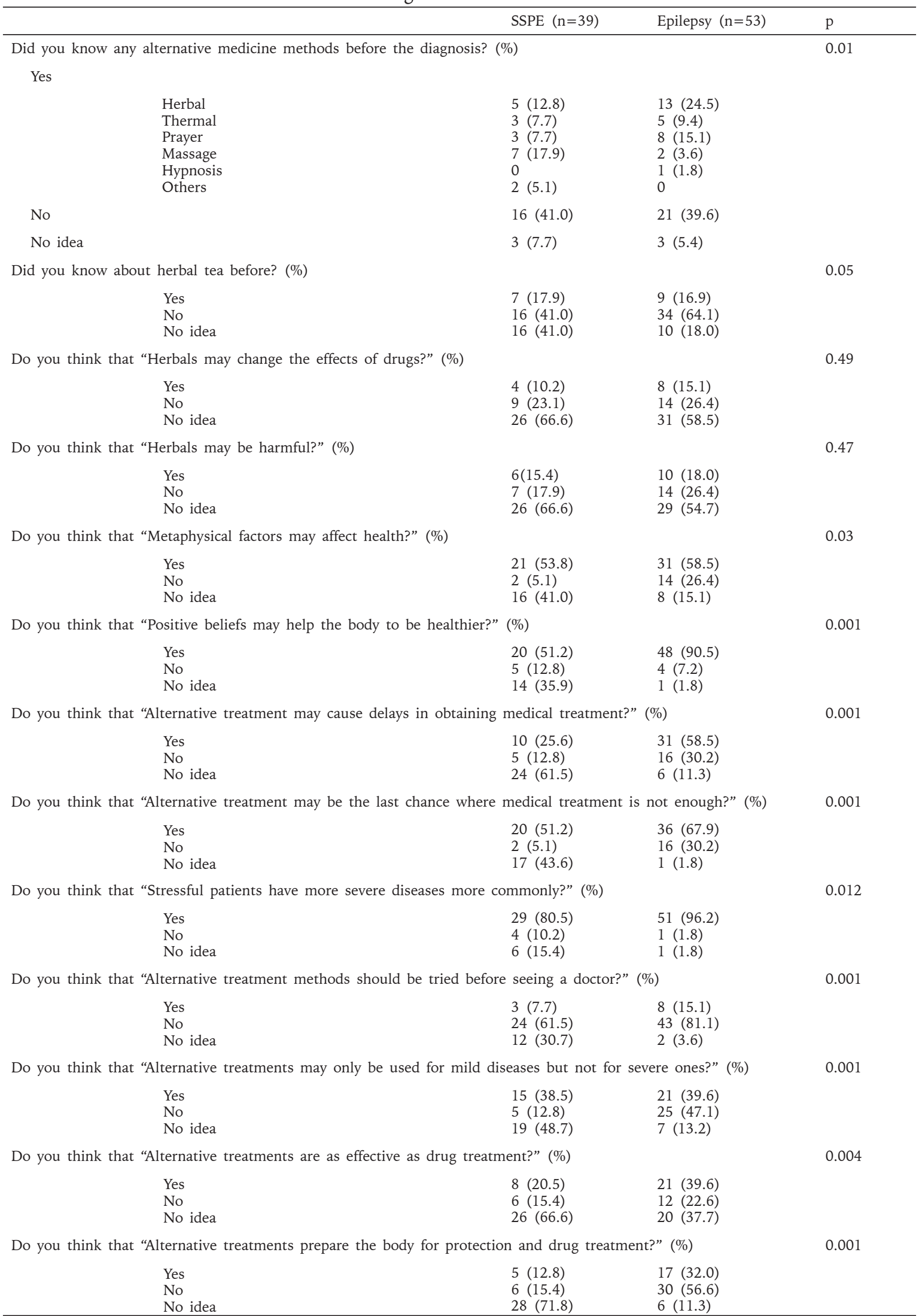


Table III. Evaluation of Behavior Pattern of Parents About Alternative Medicine.

\begin{tabular}{ccc}
\hline & SSPE $(\mathrm{n}=39)$ & Epilepsy $(\mathrm{n}=53)$ \\
\hline Were you informed & & \\
Yes & & \\
No & $26(66.6)$ & $41(77.4)$ \\
No idea & $3(7.7)$ & $3(5.6)$ \\
& $10(25.6)$ & $9(16.9)$
\end{tabular}

What do you know about the course of the disease? (\%)

Fast recovery
Slow recovery
Variable
No idea

Time passed after the diagnosis (\%)

$$
\begin{aligned}
& \text { 2-6 months } \\
& \text { 7-12 months } \\
& \text { 13-24 months } \\
& >25 \text { months }
\end{aligned}
$$

0

$8(20.5)$

$12(30.8)$

19 (48.7)
$10(25.6)$

5 (12.8)

3 (7.7)

21 (53.8)
0.01

$14(26.4)$

19(35.8)

$9(16.9)$

$11(20.7)$

0.19

$22(41.5)$

8 (15.1)

6 (11.3)

17 (32.1)

Did you apply any alternative medicine method to your child before the diagnosis? (\%)

\section{Yes}

No
$9(23.1)$

$30(76.9)$

Did you apply any alternative methods after the diagnosis? (\%)

No
Herbal treatment
Charm
Sepulcher
Whiff
Massage
Other
Two of them
More than two

Who suggested you to use alternative treatments? (\%)

Mother-mother in law
Neighbor
Friend
Doctor
Pharmacist
Other
Two of them
More than two

What was the reason of using alternative treatment methods? (\%)

Treatment
Trying
Stop progression
Psychological
treatment
Other
Two of them
More than two

Did you talk to your doctor about this treatment? (\%)

$$
\begin{aligned}
& \text { Yes } \\
& \text { No }
\end{aligned}
$$

Did you get any benefit from this treatment? (\%)

$$
\begin{aligned}
& \text { No } \\
& \text { Yes, a bit } \\
& \text { Yes, highly. } \\
& \text { I have just started } \\
& \text { I am not sure }
\end{aligned}
$$

$10(25.6)$

$3(7.7)$

$1(2.6)$

$1(2.6)$

$1(2.6)$

$3(7.7)$

$5(12.8)$

$5(12.8)$

$11(28.2)$

$13(33.2)$

16 (41.0)

$8(20.5)$
1 (1.8)

$52(98.2)$

$$
\begin{aligned}
& 45(84.9) \\
& 2(3.6) \\
& 5(9.0) \\
& 0 \\
& 2(3.6) \\
& 0 \\
& 0 \\
& 0 \\
& 0
\end{aligned}
$$$$
0
$$$$
0
$$

0.002

$$
3 \text { (5.4) }
$$

0.01

0.001

0.001

$\begin{array}{ll}10(25.6) & 5(9.0) \\ 3(7.7) & 0 \\ 2(5.1) & 0 \\ 1(2.6) & 1(1.8) \\ 3(7.7) & 0 \\ 5(12.8) & 1(1.8) \\ 5(12.8) & 1(1.8)\end{array}$

0.02

0

8 (15.1)

0.42

$\begin{array}{ll}7(17.9) & 1(1.8) \\ 9(23.1) & 2(3.6) \\ 5(12.8) & 1(1.8) \\ 0 & 1(1.8) \\ 8(20.5) & 3(5.4)\end{array}$

1 (1.8)

$1(1.8)$

$1(1.8)$

2 (5.1)

27 (69.2)

0

$8(15.1)$

$26(66.6) \quad 6(11.3)$

$\begin{array}{ll}3(7.7) & 2(3.6)\end{array}$

Together with classical treatment

Without classical treatment

$3(7.7)$

0.06

How much money did you pay for this treatment? (\%)

$$
\begin{aligned}
& \text { None } \\
& 1-50 \text { TL }(\approx 1-16 \$) \\
& 51-150 \text { TL }(\approx 17-50 \$) \\
& >150 \text { TL }(>50 \$)
\end{aligned}
$$

$\begin{array}{ll}7(17.9) & 4(7.2) \\ 1(2.6) & 1(1.8) \\ 3(7.7) & 1(1.8) \\ 18(46.2) & 1(1.8)\end{array}$


higher educational level of the parents in the epilepsy group. Alternative treatment methods were regarded as an addition to medical drugs in most SSPE (26/29) and epilepsy (6/8) patients. This indicates a high degree of reliance of parents to their doctors. Tonekaboni et al. ${ }^{11}$ reported that $44 \%$ of 133 parents or relatives of epileptic children had used alternative methods either alone or in combination with other treatments and only $16.7 \%$ of these parents had discussed this matter with their children's physicians. In our study, 13 of 29 parents in SSPE group and none of the 8 parents in the epilepsy group informed their doctors about using alternative treatment methods. Al Asmi et al. ${ }^{12}$ reported that $73.3 \%$ of their 101 participants were using alternative treatment methods. Similar to ours, the most common types of alternative treatment methods reported were under the "mind-body" type (incantations and incense) and herbs. They also reported an association of using alternative treatment methods with unemployment, having basic school education and low family income ${ }^{12}$. In our study population, the educational levels and family income rates of parents were in the lower range and this may be one of the reasons of high application rates of alternative medicine methods in the SSPE group.

Very recently, Hartmann et al. ${ }^{13}$ studied 164 parents and reported that $13 \%$ stated that they used alternative medicine methods in their child. The main reason of using alternative medicine was reported as the adverse events associated with anti-convulsant medications. Among those 21 parents, ten parents described positive effects of alternative medicine on seizure frequency and 12, on the general condition of their child. In our study, the main reason for using these methods was "treatment" in both groups. The benefit rates of these agents reported by $14 / 29$ in SSPE group and $3 / 8$ in epilepsy group are similar to those reported by Hartman et al. ${ }^{13}$ Differences between results of different studies may be related to cultural differences, educational level, time after diagnosis (parents becoming more interested in these treatment methods in time), and the importance of alternative treatment methods for investigators, patients or caregivers.

There are some limitations to be emphasized in this study. The first one is that the questionnaires were filled out by the parents and then collected by the doctors during interview, which might have caused underreporting. Results may be different in studies where the physician is blind to the answers. On the other hand, even with this drawback we observed a high usage of alternative and complementary methods, especially in SSPE. This may be associated with the lack of effective treatment, discouragement, and loss of expectations from medical approach that may affect the parental behavior and the results point to need for more professional help and support for such particular disease groups.

SSPE is a chronic debilitating disease where as high as $75 \%$ of parents of SSPE patients use alternative treatment methods for their children. Most of the parents define this treatment as complementary for the traditional drug treatments. However, less than half of the parents of SSPE patients reported that they had talked with their doctors about this condition. The results suggest that parents need more support and information by the medical staff. Larger studies are warranted with different patient groups to define the general behavior pattern of parents of SSPE patients about alternative treatment methods. Moreover, the interference of this treatment with the regular treatment needs to be considered and treatment doses adjusted accordingly.

\section{Acknowledgements}

The author wishes to thank the participants, the families, and Professor Dr Banu Anlar (Department of Pediatric Neurology, Hacettepe University, Faculty of Medicine, Ankara, Turkey).

\section{REFERENCES}

1. Gutierrez J, Issacson RS, Koppel BS. Subacute sclerosing panencephalitis: an update. Dev Med Child Neurol 2010; 52: 901-907.

2. Campbell H, Andrews N, Brown KE, Miller E. Review of the effect of measles vaccination on the epidemiology of SSPE. Int J Epidemiol 2007; 36: 1334-1348.

3. Anlar B, Kose G, Gurer Y, et al. Changing epidemiological features of subacute sclerosing panencephalitis. Infection 2001; 29: 192-195.

4. Katz SL. A vaccine-preventable infectious disease kills half a million children annually (Editorial). J Infect Dis 2005; 192: 1679-1680. 
5. Gascon GG. Randomized treatment study of inosiplex versus combined inosiplex and intraventricular interferon-alpha in subacute sclerosing panencephalitis (SSPE): international multicenter study. J Child Neurol 2003; 18: 819-827.

6. National Institutes of health. More than one third of US adults use complementary and alternative medicine, according to new government survey. [Serial online] 2004. Available from: http://nccam. nih.gov/ news/2004/052704.htm.

7. Jackson CF, Makin SM, Marson AG, Kerr M. Nonpharmacological interventions for people with epilepsy and intellectual disabilities. Cochrane Database Syst Rev 2015; 9: CD005502.

8. Ekici B, Tatlı B, Abalı S, Aydınlı N, Özmen M. Application of complementary and alternative medicine in epileptic children at a tertiary pediatric neurology center in Turkey. Eur J Integr Med 2011; 4: e71-e75.
9. Peebles CT, McAuley JW, Roach J, Moore JL, Reeves AL. Alternative medicine use by patients with epilepsy. Epilepsy Behav 2000; 1: 74-77.

10. Lagunju IA. Complementary and alternative medicines use in children with epilepsy in Ibadan, Nigeria. Afr J Med Med Sci 2013; 42: 15-23.

11. Tonekaboni SH, Jafari Naeini S, Khajeh A, et al. Use of complementary and alternative medicine for epileptic children in tehran: a cross-sectional study (2009-2011). Iran J Child Neurol 2014; 8: 26-31.

12. Al Asmi A, Al Maniri A, Al-Farsi YM, et al. Types and sociodemographic correlates of complementary and alternative medicine (CAM) use among people with epilepsy in Oman. Epilepsy Behav 2013; 29: 361-366.

13. Hartmann N, Neininger MP, Bernhard MK, et al. Use of complementary and alternative medicine (CAM) by parents in their children and adolescents with epilepsy - Prevelance, predictors and parents' assessment. Eur J Paediatr Neurol 2016; 20: 11-19. 